\title{
A PRODUÇÃO DA VIDA NUA NO ESTADO DE GUERRA GLOBAL
}

\section{THE PRODUCTION OF NAKED LIFE IN THE STATE OF GLOBAL WAR}

\author{
Maiquel Angelo Dezordi Wermuth*
}

\begin{abstract}
RESUMO: o artigo analisa os contornos biopolíticos do combate ao terrorismo no ambiente de guerra global. A biopolítica é apresentada como o movimento por meio do qual se dá a implicação da vida natural do homem nos mecanismos e nos cálculos do poder. Nesse rumo, é o estudo da biopolítica que viabiliza a compreensão dos motivos pelos quais o homem da contemporaneidade encontra-se exposto a uma violência sem precedentes, o que permite falar a respeito de um patamar de indistinção entre direito e violência, na medida em que o estado de exceção se transforma no paradigma dominante da política. A figura do homo sacer é apresentada como emblemática para a compreensão deste espaço anômico, ou seja, deste ambiente no qual aquilo que é excluído da norma geral não está, em razão disso, absolutamente fora de relação com a norma, mas se mantém em relação com ela na forma da suspensão: a norma se aplica à exceção desaplicando-se.
\end{abstract}

PALAVRAS-CHAVE: Biopolítica. Estado de exceção. Guerra global. Terrorismo.

ABSTRACT: The paper analyses the biopolitical boundaries of the fight against terrorism in the global war environment. The Biopolitics is presented as the movement through which natural human life is implicated in the ways and calculations of the power. In this perspective, it is the study of the Biopolitics that makes it possible to understand the motives by which the contemporary man finds himself exposed to an unprecedented violence that allows to talk about a level of no distinction between right and violence, once the state of exception changes into a dominant paradigm of politics. The homo sacer is presented as allegorical, in order to understand such an atypical space, $i$. e., an environment in which the element excluded from the general norm is not, because of that, absolutely out of relation with it, but is kept in relation to the mentioned norm as a form of suspension: the norm applies to the exception by disapplying itself.

KEYWORDS: Biopolitics. Global war. State of exception. Terrorism.

\section{INTRODUÇÃO}

Os atentados terroristas que ocorreram em grandes centros urbanos no início do novo milênio deflagraram sinais de alerta nas políticas de segurança dos mais diversos países, suscitando a discussão sobre a capacidade dos poderes públicos em dar respostas efetivas a esses problemas. Invariavelmente, os discursos de enfrentamento ao que se convencionou

\footnotetext{
* Doutor em Direito Público pela Unisinos. Professor dos Cursos de Graduação em Direito da Unijuí e Unisinos. Professor do Mestrado em Direitos Humanos da Unijuí.E-mail: madwermuth@gmail.com Revista da Faculdade de Direito - UFPR, Curitiba, vol. 60, n. 1, jan./abr. 2015, p. 117-136.
} 
chamar de terrorismo internacional perpassam pela necessidade de relativização dos limites da dominação que pode ser exercida pelos órgãos estatais. A flexibilização de garantias como, por exemplo, o direito à liberdade e à intimidade, passou a ser tolerada e até mesmo defendida como imprescindível em nome da eficácia que o combate requer.

Em um contexto tal, a partir do momento em que ditas flexibilizações passaram a ocorrer de modo sistemático, contaminando as legislações de diversos países, verifica-se que o estado de exceção encapsulado a duras penas no bojo dos Estados Democráticos de Direito contemporâneos vem sendo paulatinamente desvelado. Não é raro que, na busca por formas eficientes de combate às novas formas assumidas pela criminalidade, os Estados lancem mão da tortura, do sequestro e do campo extralegal como instrumentos para a garantia da segurança. Libera-se, dessa forma, a violência dominante de suas limitações, o que conduz à constatação de que as democracias ocidentais não parecem capazes de enfrentar o terrorismo internacional sem a utilização de instrumentos e estratégias que minam os valores sobre os quais se encontram assentadas.

Nesse rumo, o objetivo do presente artigo é discutir, em um primeiro momento, a produção de vida nua (não qualificada politicamente) como principal consequência da persecução ao terrorismo no estado de "guerra global" para, em um segundo momento, compreender a temática a partir de seus contornos biopolíticos. A obra de Giorgio Agamben e Michel Foucault será o referencial teórico que conduzirá a discussão.

\section{O COMBATE AO TERRORISMO NO ESTADO DE "GUERRA GLOBAL": A PRODUÇÃO DE VIDA NUA}

O terrorismo pode ser visto como um dos "novos riscos" que mais obrigou o Estado a se reinvestir nas suas funções, inclusive com limitações consideráveis ao exercício de determinadas liberdades públicas pelos cidadãos, por ocasião da colocação da segurança como uma das prioridades da agenda política. Na seara jurídico-penal, a tragédia envolvendo as torres gêmeas em Nova Iorque pode ser vista como o estopim de uma nova doxa punitiva, pautada pela noção de guerra. Com efeito, segundo Hardt e Negri (2005, p. 22-3), este evento obrigou ao reconhecimento de uma situação de "guerra global", que se transforma em uma “condição geral". É fato notório que "em determinados momentos e lugares, pode haver cessação das hostilidades, mas a violência letal está presente como potencialidade constante, sempre pronta a irromper em qualquer lugar." 
Em um ambiente assim o medo, compreendido como sentimento de vulnerabilidade, converteu-se em um condicionante importante das políticas de segurança, sendo utilizado como escusa perfeita para evitar a perda de velocidade de projetos neoliberais hegemônicos. Criaram-se inimigos com o objetivo único de eliminar toda resistência às estratégias das posições dominantes. Com efeito, antes de terem efetivamente inaugurado uma nova era da política internacional, os eventos de 11 de setembro de 2001 apenas trouxeram à tona processos que já se alastravam há longa data no cenário político. Muitas das medidas securitárias adotadas após os atentados foram gestadas muito antes desses acontecimentos. O que faltava para elas emergirem era apenas um bom pretexto. E a guerra ao terrorismo constituiu uma justificativa perfeita.

Com isso, o estado de exceção - paradoxalmente - transforma-se na regra, ocupando o espaço da normalidade, o que faz com que se torne cada vez mais obscura a distinção tradicional entre guerra e política, dado que "a guerra vai-se transformando no princípio básico de organização da sociedade, reduzindo-se a política apenas a um de seus recursos ou manifestações." (HARDT; NEGRI, 2005, p. 33).

Na teorização de Agamben (2004, p. 13), o estado de exceção "tende cada vez mais a se apresentar como o paradigma de governo dominante na política contemporânea". Para o autor (2010, p. 44), “o espaço ‘juridicamente vazio’ do estado de exceção [...] irrompeu de seus confins espaço-temporais e, esparramando-se para fora deles, tende agora por toda parte a coincidir com o ordenamento normal, no qual tudo se torna assim novamente possível."

Esse transbordamento do estado de exceção é visualizado por Agamben (2004) como uma tendência em ato em todas as democracias ocidentais, nas quais a declaração de um estado de exceção é progressivamente substituída por uma generalização sem precedentes do paradigma da segurança como técnica normal de governo. A ideia agambeniana é demonstrar que "o estado de exceção independe progressivamente da ameaça bélica, que originalmente o justificava, desloca-se até as situações de emergência econômica (crises econômicas, desvalorizações drásticas) e finalmente converte-se em uma prática habitual.” (CASTRO, 2012, p. 77).

\footnotetext{
${ }^{1}$ A teorização agambeniana acerca do estado de exceção parte da polêmica e amplamente conhecida formulação de Carl Schmitt (1988, p. 15), que introduz sua obra Teologia política com a seguinte definição: "Soberano é aquele que decide do estado de exceção". Para Schmitt (Ibid., p. 17), o texto constitucional não pode prever em que momento se tornará necessário o reconhecimento da exceção, mas pode definir "quem tem o direito de intervir nesses casos". Nesse sentido, o soberano "está na margem da ordem jurídica normalmente em vigor, estando ao mesmo tempo submetido a ela, pois a ele incumbe decidir se a Constituição deve ser suspensa em sua totalidade". Logo, a decisão do soberano pela exceção "se libera de toda obrigação normativa e torna-se absoluta em sentido próprio. No caso de exceção, o Estado suspende o direito em virtude de um direito de autoconservação" (Ibid., p. 22).
}

Revista da Faculdade de Direito - UFPR, Curitiba, vol. 60, n. 1, jan./abr. 2015, p. 117-136. 
Efetivamente, por meio do estado de exceção, o soberano cria e garante uma situação da qual o direito tem necessidade para a sua própria vigência. Em outros termos, "somente porque a validade do direito positivo é suspensa no estado de exceção, ele pode definir o caso normal como âmbito da própria validade.” (AGAMBEN, 2010, p. 24). Pode-se afirmar, então, que o Estado moderno é "a um só tempo, constituinte e constituído, fundador de sua própria lógica jurídica e por ela mesma fundamentado", de sorte que "o Estado moderno vive sob a constante ameaça de um ato extrajurídico, capaz de depô-lo de seu pedestal.” (MARTINS, 2008, p. 166).

Efetivamente, a exceção é uma espécie de exclusão singular, no que se refere à norma geral. O que a caracteriza é justamente o fato de que aquilo que é excluído não permanece, em razão disso, fora de relação com a norma, mas mantém esse relacionamento sob a forma de suspensão, o que significa dizer que a norma se aplica à exceção desaplicandose, ou seja, retirando-se desta. Desse modo, "não é a exceção que se subtrai à regra, mas a regra que, suspendendo-se, dá lugar à exceção e somente deste modo se constitui como regra, mantendo-se em relação com aquela." (AGAMBEN, 2010, p. 24-5).

O paradoxo, aqui, é que a exceção representa justamente uma exclusão inclusiva: aquilo que em nenhum caso pode ser incluído vem a ser incluído na forma de exceção. No estado de exceção, portanto, torna-se impossível distinguir a transgressão da lei e a sua execução: nele, o que está de acordo com a norma e o que a viola coincidem sem resíduos. A partir do momento em que o exercício da soberania deságua na deflagração do estado de exceção, o nexo original entre violência e direito é mantido. A violência exercitada no estado de exceção não conserva nem simplesmente põe o direito, "mas o conserva suspendendo-o e o põe excetuando-se dele." (AGAMBEN, 2010, p. 69).

Nesse rumo, o estado de exceção designa um estado da lei no qual a norma está em vigor, porém não se aplica, porque não tem força. Por outro lado, atos que não têm valor de lei adquirem essa sua força. Logo, “o estado de exceção é um espaço anômico onde o que está em jogo é uma força de lei sem lei." (AGAMBEN, 2004, p. 61). Isso significa que "para aplicar uma norma, é necessário, em última análise, suspender sua aplicação, produzir uma exceção", razão pela qual se pode afirmar que o estado de exceção "marca um patamar onde lógica e práxis se indeterminam e onde uma pura violência sem logos pretende realizar um enunciado sem nenhuma referência real." (AGAMBEN, 2004, p. 63).

Essas ideias de força de lei separada da lei, de vigência sem aplicação, são algumas das ficções das quais, na ótica de Agamben (2004), o direito lança mão no intuito de incluir em si sua própria ausência, apropriando-se do estado de exceção ou, pelo menos, assegurando 
uma relação com ele. A força de lei sem lei, ou "força de lei" - como designa o autor (2004, p. 50) - representa, assim, a antítese da lei, uma vez que obriga, mesmo não reunindo as condições formais para tanto.

Agamben não limita a discussão sobre o estado de exceção ao campo teórico: ao contrário, salienta que um dos interesses da sua pesquisa é justamente demonstrar concretamente - de que modo a exceção se transforma no paradigma dominante da política contemporânea. E é justamente nas medidas adotadas pelos Estados Unidos, no período pós 11 de setembro de 2001, no combate ao terrorismo, que o filósofo italiano busca argumentos para afirmar que "a novidade da 'ordem' do presidente Bush está em anular radicalmente todo estatuto jurídico do indivíduo, produzindo, dessa forma, um ser juridicamente inominável e inclassificável.” (AGAMBEN, 2004, p. 14).

Segundo o autor (2004, p. 14), os homens capturados no Afeganistão e presos em Guantánamo não gozam do estatuto de prisioneiros de guerra segundo a Convenção de Genebra, bem como não são considerados acusados pelas leis norte-americanas. Quer dizer: “nem prisioneiros nem acusados, mas apenas detainees, são objeto de uma pura dominação de fato, de uma detenção indeterminada não só no sentido temporal mas também quanto à sua própria natureza, porque totalmente fora da lei e do controle judiciário." (AGAMBEN, 2004, p. 14). Situações como a dos presos de Guantánamo repristinam os horrores dos campos de concentração nazistas, afinal, o campo não é outra coisa senão o "espaço que se abre quando o estado de exceção começa a tornar-se a regra." (AGAMBEN, 2010, p. 164, grifo do autor). Isso porque, no campo, o estado de exceção deixa de ser uma suspensão temporal do ordenamento com base numa situação factícia de perigo e adquire uma disposição espacial permanente que se mantém, no entanto, estavelmente fora do ordenamento normal ${ }^{2}$.

Ao comentar as fotografias dos prisioneiros de Guantánamo divulgadas pelo Departamento de Defesa dos EUA, Butler (2009, p. 104) refere que eles se assemelham a animais enjaulados, o que, segundo a autora, representa um processo de "bestialización de lo humano", ou seja, os prisioneiros são considerados "algo menos que humanos, que de algún modo asumen forma humana". Pode-se afirmar, portanto, que eles representam "una equivocación de lo humano, lo que explica en buena parte el esceptismo acerca de la aplicabilidad de leyes e derechos."

\footnotetext{
${ }^{2}$ Em seu estudo acerca da situação dos judeus capturados em Auschwitz, Agamben (2008, p. 57) refere que o campo configura "exatamente o lugar em que o estado de exceção coincide, de maneira perfeita, com a regra, e a situação extrema converte-se no próprio paradigma do cotidiano." 
A figura do muçulmano ${ }^{3}$ dos campos de concentração nazistas é então repristinada nos prisioneiros de Guantánamo: enquanto perfeita demonstração de uma situação extrema por excelência, o campo permite a decisão soberana sobre o que é humano e sobre o que não merece tal status. Os prisioneiros de Guantánamo, assim como os judeus capturados em Auschwitz, representam a imagem de "um ser indefinido, no qual não só a humanidade e a não-humanidade, mas também a vida vegetativa e a de relação, a fisiologia e a ética, a medicina e a política, a vida e a morte transitam entre si sem solução de continuidade." (AGAMBEN, 2008, p. 56). Ao matar, o poder se autossuprime, mas ao submeter as vítimas a uma situação de fome e degradação, o poder ganha tempo, o que lhe permite a fundação de um terceiro reino entre a vida e a morte, de forma a atestar o seu triunfo sobre a humanidade do homem. Tal afirmação significa que esse terceiro reino "é a cifra perfeita do campo, do não-lugar onde todas as barreiras disciplinares acabam ruindo, todas as margens transbordam." (AGAMBEN, 2008, p. 56).

Em um contexto tal, a desrealização do outro quer dizer que não está nem vivo nem morto, mas em uma interminável condição de espectro. Assim, a paranoia infinita que vê a guerra contra o terrorismo como uma guerra sem fim se justifica incessantemente em relação com a infinitude espectral de seu inimigo, sem considerar se há ou não bases firmes para suspeitar da existência de células terroristas em contínua atividade (BUTLER, 2009).

Ao se debruçar sobre o caso específico da indefinite detention em Guantánamo, Butler (2009) assevera que, em nome de alertas de segurança e de um estado de emergência, a lei acaba sendo suspensa em plano nacional e internacional e, juntamente com esse ato, impõe-se um novo estado de soberania que não somente se exerce fora da lei, mas também se constrói por meio da criação de uma burocracia administrativa na qual os funcionários, além de decidir quem será julgado e quem será detido, são também os que têm a última palavra acerca da detenção indefinida de uma pessoa. Por meio dessa ação de suspensão da lei, o Estado "produce una ley que no es una ley, una corte que no es una corte, un proceso que no es un proceso", quer dizer, o estado de exceção "retrotrae el funcionamiento del poder de un conjunto de leyes (judiciales) a un conjunto de normas (gubernamentales) que restablecen el poder soberano", sendo que essas normas são "completamente discrecionales, incluso arbitrarias, ejercidas por funcionarios que las interpretan unilateralmente y que deciden las condiciones y la forma en que son invocadas.” (BUTLER, 2009, p. 91-2, grifos da autora).

\footnotetext{
${ }^{3}$ A expressão muçulmano era utilizada nos campos de concentração nazistas para designar os prisioneiros enfermos, uma vez que sua imagem prostrada, quando observados de longe, fazia lembrar-se de árabes em oração.
} 
Nesse contexto, a lei não é aquilo a que o Estado está sujeito, tampouco representa um critério de aferição da (i)legitimidade de um ato de governo: ela é compreendida como um mero instrumento, ou seja, um dispositivo de poder que pode ser aplicado ou suspenso à vontade. Afinal, é o Executivo, nesses casos, que avalia que determinado indivíduo ou grupo constituem um perigo para o Estado. No entanto, dita avaliação é realizada em um contexto de emergência, no qual o Estado pode exercer prerrogativas de poder que compreendem a suspensão da lei. Nesses casos, são os decretos, as medidas emanadas pelo Poder Executivo que, mesmo não sendo leis, possuem força de lei, o que, na ótica de Agamben (2004), é uma constante dos séculos XX e XXI, nos quais o chefe do Executivo cada vez mais tem atuado de forma decisiva, promovendo uma verdadeira confusão entre a clássica divisão de poderes.

Em um contexto tal, avaliar alguém como perigoso é suficiente para convertê-lo em perigoso e justificar sua detenção indefinida, ou seja, transformá-lo em um mero objeto nas mãos do Estado, evidenciando, em pleno século XXI, uma repristinação da figura do homo sacer, obscura figura do direito arcaico romano resgatada por Agamben (2010) para retratar justamente a ambivalência que é característica do estado de exceção, bem como para dar conta da complexidade da situação do homem contemporâneo. O homo sacer, assim, é a figura encontrada pelo autor justamente por situar-se na zona de indistinção entre a violência e o direito. O bando ${ }^{4}$ soberano, que exclui incluindo e que representa, para o autor, a forma pura da lei, permite a compreensão dessa figura arcaica: como na exceção soberana a lei se aplica de fato ao caso excepcional desaplicando-se, ou seja, retirando-se desse, o homo sacer é aquele ser que não é consagrado ${ }^{5}$ - no sentido de passagem do ius humanun (profano) para o divino (sacro) - mas que também é posto para fora da jurisdição humana. Portanto, a vida sacra é aquela que, ao mesmo tempo em que é insacrificável, é também matável, sem que o ordenamento jurídico sancione quem porventura a eliminar.

\footnotetext{
${ }^{4}$ De acordo com Giacoia Junior (2008, p. 283), "bando é a tradução portuguesa do termo alemão Bann, que significa o poder de governo, a soberania, o direito de estatuir comandos e proibições, de impor e executar penas; também o direito de banir. Como conceito, mantém íntima relação com o instituto da Friedlosigkeit do antigo direito germânico e a correspondente figura do Friedlos, que designam a condição daquele que, banido e proscrito, está excluído da esfera de proteção do ordenamento jurídico da comunidade de origem, e, portanto, impossibilitado de gozar do privilégio da paz assegurada por esse ordenamento. Nesse sentido, o Friedlos é o sem paz, o exposto às forças da natureza e à violência arbitrária de quem quer que seja.

Trata-se da figura do excluído, do pária cuja morte não constitui homicídio, ao qual o ordenamento que o penaliza se impõe sob a forma da suspensão de seus efeitos e da prerrogativa de sua invocação. É de se notar a homologia estrutural entre bando (Bann) exceção (exceptio, ex capere, 'capturar fora'), paradoxo sobre o qual se constrói grande parte da argumentação de Agamben."

${ }^{5}$ De acordo com Agamben (2007, p. 65-6), "consagrar (sacrare) era o termo que designava a saída das coisas da esfera do direito humano[...]. Pode-se definir como religião aquilo que subtrai coisas, lugares, animais ou pessoas ao uso comum e as transfere para uma esfera separada. Não só não há religião sem separação, como toda separação contém ou conserva em si um núcleo genuinamente religioso. O dispositivo que realiza e regula a separação é o sacrifício: através de uma série de rituais minuciosos [...] ele estabelece, em todo caso, a passagem de algo do profano para o sagrado, da esfera humana para a divina."

Revista da Faculdade de Direito - UFPR, Curitiba, vol. 60, n. 1, jan./abr. 2015, p. 117-136.
} 
Quer dizer, o que define a condição do homo sacer não é a pretensa ambivalência originária da sacralidade que lhe é inerente, mas sim o caráter particular da dupla exclusão em que se encontra preso e, consequentemente, a violência à qual se encontra exposto. Essa violência não é classificada como sacrifício e tampouco como homicídio, não é a execução de uma condenação e tampouco um sacrilégio, de modo que a sua vida é "absolutamente e simplesmente matável, objeto de uma violência que excede tanto a esfera do direito quanto a do sacrifício." (NASCIMENTO, 2012, p. 163).

A vida humana matável e insacrificável é a vida capturada no bando soberano. O préstimo original da soberania, portanto, é a produção da vida nua. Para a compreensão dessa distinção, Agamben (2010) faz uma releitura da filosofia clássica, a fim de trazer à luz os conceitos de zoé e bios: nessa dicotomia, zoé designa o simples fato de viver, a mera existência enquanto vida nua, ao passo que bios designa a vida qualificada, a vida do indivíduo ou do grupo. A retomada dessa dicotomia serve para ilustrar justamente a condição de determinados seres humanos na contemporaneidade, ou seja, para ilustrar a relação inclusão (daqueles que vivem uma vida qualificada) versus exclusão (daqueles que são relegados à condição de banimento, que vivem uma vida desqualificada) que caracteriza a política contemporânea.

Neste passo, se Guantánamo representa um lugar de não-direito, no qual a violação de direitos humanos torna-se sistemática, não se pode olvidar que aquele campo representa apenas um exemplo de uma prática que hoje é generalizada. A propósito, Agamben (2004, p. 131) salienta que o estado de exceção enquanto forma de governo continuou a funcionar quase sem interrupção a partir da Primeira Guerra Mundial, por meio do fascismo e do nacional-socialismo, até nossos dias, quando atinge exatamente seu máximo desdobramento planetário.

A partir da análise da military order, promulgada em 2001 por George W. Bush no combate ao terrorismo, é possível ilustrar como o aspecto normativo do direito pode ser “impunemente eliminado e contestado por uma violência governamental que, ao ignorar no âmbito externo o direito internacional e produzir no âmbito interno um estado de exceção permanente, pretende, no entanto, ainda aplicar o direito.” (AGAMBEN, 2004, p. 131).

Essas medidas demonstram que o Estado de direito jamais conseguiu abolir plenamente o estado de exceção, que permaneceu latente, pronto para ser utilizado toda vez que a ordem social estivesse ameaçada por qualquer pessoa ou grupo social. Nesse sentido, lembra Zaffaroni (2007, p. 170) que as “couraças” que aprisionam o Estado de polícia no seio do Estado de Direito não o eliminaram de forma absoluta, mas apenas o encapsularam. 
Agamben (2010) também ressalta a contradição: o Estado de direito, que pensa ter abolido a vontade soberana, apenas a encapsulou, ou seja, ela permanece oculta para ser utilizada quando for necessário.

Assim, quando uma pessoa ou um grupo populacional se transforma em uma ameaça à ordem, o Estado pode se utilizar da exceção jurídica para separar os direitos da cidadania da mera vida nua. Segundo Ruiz (2012, p. 12), “essa separação possibilita expulsar para fora do direito a vida que se pretende controlar na forma de exceção." E, "na exceção o direito suspenso torna a vida humana um homo sacer exposto à fragilidade da violação sem que o direito possa ser invocado para protegê-lo." A figura da exceção, em determinadas circunstâncias, permite, então, a suspensão do direito de certas pessoas ou grupos, transformando a vida em vida nua.

Ocorre que, na medida em que as decisões excepcionais vão se tornando mais habituais, a exceção tende a se transformar em normalidade e, nesse rumo, "o uso constante da exceção como forma de controle das vidas 'perigosas', torna-a uma técnica política de governo da vida humana amplamente utilizada pelos Estados modernos.” (RUIZ, 2012, p. 22). A particularidade da exceção jurídica moderna reside justamente nesse ponto: na sua eficiente versatilidade como técnica de governo de grupos ou classes sociais considerados indesejados ou perigosos, segundo os critérios de quem tem o poder para assim considerá-los, ou seja, a vontade soberana.

Assiste-se, assim, em meio à paranoia securitária contemporânea decorrente da busca pela prevenção a todo custo contra novas investidas terroristas, a um incremento da biopolítica, ou seja, da cada vez maior implicação da vida natural (zoé) do homem nos mecanismos e cálculos do poder. Com efeito, esta categoria foucaultiana (2008a, 2008b, 2010, 2012) assume o papel de uma importante ferramenta conceitual para o diagnóstico e a compreensão das crises políticas da contemporaneidade. Afinal, segundo Agamben (2010, p. 118), esse irromper da biopolítica representa apenas a culminância de um processo: "antes de emergir impetuosamente à luz do nosso século [século XX], o rio da biopolítica, que arrasta consigo a vida do homo sacer, corre de modo subterrâneo, mas contínuo." É com esse tema que se ocupa o tópico que segue. 


\section{OS CONTORNOS BIOPOLÍTICOS DA PRODUÇÃO DA VIDA NUA NO ESTADO DE "GUERRA GLOBAL"}

Na concepção de Foucault (2010, p. 201), a biopolítica, ou seja, essa "assunção da vida pelo poder" ou "estatização do biológico", foi "um dos fenômenos fundamentais do século XIX” e representa um câmbio importante em relação à teoria clássica da soberania: se na teoria clássica da soberania o soberano, ao deter o poder em relação à vida e à morte do súdito, poderia fazê-lo morrer ou deixá-lo viver, a biopolítica é o fenômeno que vai completar esse velho direito de soberania "com outro direito novo, que não vai apagar o primeiro, mas vai penetrá-lo, perpassá-lo, modificá-lo, e que vai ser um direito, ou melhor, um poder exatamente inverso: poder de 'fazer' viver e de 'deixar' morrer." (FOUCAULT, 2010, p. 202). Faz-se viver, e abandona-se à morte, portanto.

Foucault (2012) procura, então, demonstrar o importante deslocamento que ocorreu na passagem do século XVIII para o século XIX na forma de exercício do poder soberano: ele deixa de se afirmar enquanto um poder de "matar a vida" e passa a fazê-lo enquanto um poder que "gerencia a vida", um poder que tem por objetivo o saneamento do corpo da população de modo a depurá-lo de todas as infecções internas. O poder, agora, passa a ser exercido sobre a vida, fixando-se ao longo de todo o seu desenrolar.

Retomando esse tema, Agamben (2010, p. 122) refere que a grande metáfora hobbesiana do Leviatã, cujo corpo é formado pelos corpos de todos os indivíduos que compõem a sociedade, deve ser lida sob esta luz, uma vez que "são os corpos absolutamente matáveis dos súditos que formam o novo corpo político do Ocidente.” Para Esposito (2006, p. 8), nunca, na época antiga e medieval, a conservação da vida enquanto tal constituiu o objetivo prioritário da atuação política como ocorreu precisamente na Idade Moderna. E é a partir dessa perspectiva que, segundo Agamben (2010, p. 124-5), as declarações de direitos não podem ser compreendidas como meras proclamações gratuitas de valores eternos metajurídicos (por meio das quais o legislador restaria vinculado ao respeito pelos princípios éticos eternos), mas que devem ser compreendidas de acordo com a função histórica que desempenham efetivamente na formação do moderno Estado-nação: elas representam, nesse rumo, "o local em que se efetua a passagem da soberania régia de origem divina à soberania nacional"; sua função é assegurar "a exceptio da vida na nova ordem estatal que deverá suceder à derrocada do ancien régime." O fato de que

através delas, o 'súdito' se transforme [...] em 'cidadão', significa que o nascimento - isto é, a vida nua natural como tal - torna-se aqui pela primeira vez (com uma transformação cujas consequências biopolíticas somente hoje podemos começar a mensurar) o portador imediato da soberania. (AGAMBEN, 2010, p. 125)

Revista da Faculdade de Direito - UFPR, Curitiba, vol. 60, n. 1, jan./abr. 2015, p. 117-136. 
Para o autor, portanto, as declarações de direitos - desde a Declaração de Direitos do Homem e do Cidadão (1789) - são o locus da inscrição moderna da biopolítica.

Em Agamben (2010, p. 125), o corpo do "sujeito soberano", fundamento do novo Estado-nação, representa a reunião dos princípios de natividade e de soberania que haviam sido separados no Antigo Regime, no qual o nascimento dava lugar ao súdito. Em razão disso, não é possível compreender o desenvolvimento e a vocação biopolítica do Estado moderno nos séculos XIX e XX, "se esquecermos que em seu fundamento não está o homem como sujeito político livre e consciente, mas, antes de tudo, a sua vida nua, o simples nascimento que, na passagem do súdito ao cidadão, é investido como tal pelo princípio de soberania." Há, aqui, uma ficção implícita de que o "nascimento torne-se imediatamente nação, de modo que entre os dois termos não possa haver resíduo algum.” Desse modo, "os direitos são atribuídos ao homem [...], somente na medida em que ele é o fundamento, imediatamente dissipante (e que, aliás, não deve nunca vir à luz como tal), do cidadão."

Isso significa dizer, portanto, que as declarações de direitos, ao mesmo tempo que podem ser compreendidas enquanto instrumentos de garantia de direitos individuais e liberdades públicas, também podem ser vistas como instrumentos de ressignificação e investimento político da vida nua no corpo do Estado-nação. Assim, "ao lado da função emancipatória das declarações de direitos fundamentais, seria também indispensável perceber que elas integram o dispositivo de abandono da vida nua à violência dos mecanismos de poder." (GIACOIA JUNIOR, 2008, p. 284).

O processo de inscrição da vida nua na política por meio da biopolítica é um dos temas sobre os quais a análise foucaultiana dos mecanismos de poder vai se debruçar. $\mathrm{O}$ filósofo francês chega aos conceitos de biopolítica e biopoder quando vislumbra um câmbio operado ao longo dos séculos XVII e XVIII - sobretudo na virada para o século XIX - da forma como se estrutura o poder: se antes ele era a soma de micropoderes disciplinares que tinham por objetivo a administração do corpo individual, ou seja, que partiam de uma visão do corpo enquanto máquina - o que se vislumbra pela gradativa formação de instituições como a escola, o hospital, o exército e a fábrica, cujos objetivos centravam-se no adestramento dos corpos individuais e na extorsão de suas forças, paralelamente ao crescimento de sua utilidade e docilidade, de modo a integrá-lo a sistemas de controle eficazes -, agora o poder disciplinador e normalizador já não mais é exercido sobre os corpos individualizados, mas sim sobre o corpo-espécie, e tampouco se encontra disseminado em instituições sociais. Ele passa a se concentrar na figura do Estado e se exerce a título de política estatal que objetiva a administração da vida e do corpo da população. 
Para Foucault (2010, p. 206), “a biopolítica lida com a população, e a população como problema político, como problema a um só tempo científico e político, como problema biológico e como problema de poder." Logo, os fenômenos que passam a ser levados em consideração, aqui, são os coletivos, ou seja, aqueles "que só aparecem com seus efeitos econômicos e políticos, que só se tornam pertinentes no nível da massa”, o que significa dizer que "a biopolítica vai se dirigir, em suma, aos acontecimentos aleatórios que ocorrem numa população considerada em sua duração.” (FOUCAULT, 2010, p. 206-7).

A biopolítica, a partir de previsões, estimativas, estatísticas e medições, vai priorizar as intervenções nos fenômenos em nível global, com o escopo de estabelecer mecanismos reguladores que, "nessa população global com seu campo aleatório, vão poder fixar um equilíbrio, manter uma média, estabelecer uma espécie de homeostase, assegurar compensações". Quer dizer: vai se preocupar em "instalar mecanismos de previdência em torno desse aleatório que é inerente a uma população de seres vivos" de forma a "otimizar [...] um estado de vida." (FOUCAULT, 2010, p. 207).

$\mathrm{Na}$ perspectiva foucaultiana, torna-se importante analisar a forma como ambos os mecanismos de poder - o disciplinar e o regulamentador -, relacionam-se: em que pese não estarem no mesmo nível, não há um processo de autoexclusão, mas de articulação. A origem das sociedades do controle contemporâneas está justamente nas técnicas disciplinares de padronização dos corpos nas instituições ao longo dos séculos XVII e XVIII e que nos séculos XX e XXI espraiam-se para a sociedade como um todo, objetivando a normalização dos indivíduos em diversas instâncias, induzindo comportamentos - como, por exemplo, determinados padrões de consumo - e fabricando subjetividades não autênticas.

O que vai permitir essa articulação entre as duas formas de exercício de poder identificadas é a norma, uma vez que ela "é o que pode tanto se aplicar a um corpo que se quer disciplinar quanto a uma população que se quer regulamentar." Logo, a sociedade de normalização não é outra coisa senão "uma espécie de sociedade disciplinar generalizada cujas instituições disciplinares teriam se alastrado e finalmente recoberto todo o espaço", ou seja, "uma sociedade em que se cruzam, conforme uma articulação ortogonal, a norma da disciplina e a norma da regulamentação." Por meio desses mecanismos - disciplina e regulamentação - o poder, a partir do século XIX, passa a incumbir-se da vida, quer dizer, “ele conseguiu cobrir toda a superfície que se estende do orgânico ao biológico, do corpo à população, mediante o jogo duplo das tecnologias de disciplina, de uma parte, e das tecnologias de regulamentação, de outra." (FOUCAULT, 2010, p. 213). 
O paradoxo que se apresenta, nesse viés, diz respeito a como conciliar o direito de matar com um exercício de poder preocupado essencialmente com a vida. A grande questão que então se coloca é como se pode exercer o poder de morte em um sistema político centrado no biopoder ${ }^{6}$.

O mecanismo que vai permitir o exercício desse poder de morte em um regime de biopoder é o racismo, compreendido a partir de uma dupla perspectiva: em um primeiro momento, o racismo pode ser visto como um meio de introduzir no domínio da vida - de que o poder se incumbiu - o corte entre o que deve viver e o que deve morrer. Para Foucault (2010, p. 214),

\begin{abstract}
no contínuo biológico da espécie humana, o aparecimento das raças, a distinção das raças, a hierarquia das raças, a qualificação de certas raças como boas e de outras, ao contrário, como inferiores, tudo isso vai ser uma maneira de fragmentar esse campo do biológico de que o poder se incumbiu; uma maneira de defasar, no interior da população, uns grupos em relação aos outros. Em resumo, de estabelecer uma cesura que será do tipo biológico no interior de um domínio considerado como sendo precisamente um domínio biológico. Isso vai permitir ao poder tratar uma população como uma mistura de raças ou, mais exatamente, tratar a espécie, subdividir a espécie de que ele se incumbiu em subgrupos que serão, precisamente, raças. Essa é a primeira função do racismo: fragmentar, fazer cesuras no interior desse contínuo biológico a que se dirige o biopoder.
\end{abstract}

Já a segunda função do racismo, revela Foucault (2010, p. 215), será legitimar a morte do "outro" a partir de uma maneira inteiramente nova, compatível com o biopoder: a partir de então, "a morte do outro, a morte da raça ruim, da raça inferior (ou do degenerado, ou do anormal), é o que vai deixar a vida em geral mais sadia; mais sadia e mais pura." A eliminação do perigo biológico representado pelo outro será legitimada, dessa maneira, conforme estiver diretamente relacionada ao fortalecimento da própria espécie ou da raça.

$\mathrm{Na}$ análise de Esposito (2006), na medida em que a vida de um povo é racialmente caracterizada, ela também é assumida como um valor supremo, devendo ser conservada incólume em sua constituição originária ou mesmo expandida para além de seus limites. Em um quadro tal, afigura-se como óbvio que a "outra vida", ou seja, a de outros povos ou outras raças, tende a ser considerada um obstáculo para este projeto, de modo que, em seu nome, deve ser sacrificada.

O refinamento da tese foucaultiana reside justamente nesse ponto: a biopolítica enquanto forma encontrada pelo Estado para "gerir a vida da população" não pode ser ingenuamente compreendida pelo seu "caráter humanitário" de administrar, por meio de

\footnotetext{
${ }^{6}$ Como objeta Foucault (2012, p. 150), "de que modo um poder viria a exercer suas mais altas prerrogativas e causar a morte se o seu papel mais importante é o de garantir, sustentar, reforçar, multiplicar a vida e pô-la em ordem?".
} 
intervenções políticas, as condições de vida da população. Há um aspecto violento desse controle, denunciado pelo autor, que reside justamente na exigência contínua e crescente da morte em massa do "outro", enquanto instrumento privilegiado para a garantia de melhores meios de sobrevivência de uma determinada população: “o poder de expor uma população à morte geral é o inverso do poder de garantir a outra sua permanência em vida." Nesse contexto, o princípio "poder matar para poder viver" se transforma no princípio de estratégia entre os Estados, com a particularidade de que "a existência em questão já não é aquela jurídica - da soberania, é outra - biológica - de uma população.” (FOUCAULT, 2012, p. 149).

Toda biopolítica é, nessa medida, também uma tanatopolítica. Na medida em que o biológico passa a refletir-se no político, toda forma de eugenia, de cisão entre o que é considerado normal e o que é considerado anormal, passa a ser justificado. Isso porque o biopoder, em nome da proteção à vida da população, encontra legitimidade para a eliminação de todo perigo a que esta vida possa estar exposta. Segundo Esposito (2006, p. 10-1, grifo do autor), "el bíos es artificialmente recortado, por una serie de umbrales, en zonas dotadas de diferente valor que someten una de sus partes al dominio violento y destructivo de otra."

Como ressalta Agamben (2010, p. 127), “uma das características essenciais da biopolítica moderna (que chegará, no nosso século [século $\mathrm{XX}$ ], à exasperação) é a sua necessidade de redefinir continuamente, na vida, o limiar que articula e separa aquilo que está dentro daquilo que está fora." Para o autor (2010, p. 135), é como se toda valorização e toda politização da vida "implicasse necessariamente uma nova decisão sobre o limiar além do qual a vida cessa de ser politicamente relevante" e passa a ser somente "vida sacra", que, como tal, pode ser impunemente eliminada. O ponto de decisão reside justamente em definir em que momento uma vida deixa de ser política (e economicamente) relevante e, consequentemente, pode ser eliminada do tecido societal.

Neste estado de coisas, o racismo é condição de possibilidade para que se possa exercer o direito de matar. Nas palavras de Foucault (2010, p. 52-3), o racismo de Estado é exercido pela sociedade sobre ela mesma, ou seja, "sobre seus próprios elementos, sobre os seus próprios produtos"; trata-se de um "racismo interno, o da purificação permanente, que será uma das dimensões fundamentais da normalização social.",

\footnotetext{
${ }^{7}$ Nesse ponto, é importante consignar que por "tirar a vida" não se compreende, na perspectiva foucaultiana (2010, p. 216), unicamente o assassínio direto, mas também tudo que pode ser considerado assassínio indireto: "o fato de expor à morte, de multiplicar para alguns o risco de morte ou, pura e simplesmente, a morte política, a expulsão, a rejeição.”
} 
Com efeito, na medida em que a biopolítica se transforma em tanatopolítica, verificase que o ponto de decisão entre o fazer viver e o fazer morrer desloca-se para áreas cada vez maiores da vida social, razão pela qual Agamben (2010) salienta que a fotografia do homo sacer pode ser buscada na imagem do refugiado, do paciente sujeito à eutanásia programada, das cobaias humanas, do comatoso, e onde mais se verifique que o homem esteja sujeito ao poder de ciência e de polícia. Žižek (2003) vai ainda mais longe, incluindo no rol do filósofo italiano os terroristas prisioneiros norte-americanos, os receptores de ajuda humanitária, os sem-papel na França, os habitantes de guetos nos EUA e de favelas no Brasil. Ao fim e ao cabo, o esloveno refere que, no nível mais elementar, somos todos objetos da biopolítica e, portanto, excluídos como o homo sacer.

Daí a afirmação de Nascimento (2012, p. 175) no sentido de que "o homem contemporâneo está exposto à violência sem precedentes", dado que "nunca antes do século vinte os homens foram expostos à morte de forma tão corriqueira e trivial, com o agravante de não se saber sê-lo”. Para ratificar sua afirmação, o autor citado recorre a alguns exemplos na realidade brasileira: os doentes nas filas dos hospitais do sistema público de saúde, os encarcerados em penitenciárias superpovoadas e insalubres, os pacientes abandonados em hospitais psiquiátricos e manicômios judiciários, os trabalhadores exaustos dos campos de cultivo e extração de cana-de-açúcar, as crianças submetidas ao trabalho escravo, os moradores de ruas dos grandes centros urbanos.

A guerra (com ela e por meio dela) e o genocídio assumem, nesse quadro, o papel de ferramentas largamente utilizadas pela biopolítica para a consecução de seus objetivos. Ao mencionar que nunca na história da humanidade as guerras foram tão sangrentas como a partir do século XIX, e tampouco os regimes políticos haviam, até então, praticado tamanhos holocaustos em suas próprias populações, Foucault (2012, p. 149) salienta que o câmbio ocorre justamente em virtude do surgimento do biopoder, de modo que o "formidável poder de morte [...] apresenta-se agora como o complemento de um poder que se exerce, positivamente, sobre a vida, que empreende sua gestão, sua majoração, sua multiplicação, o exercício, sobre ela, de controles precisos e regulações de conjunto.”

Em razão disso, já não são mais travadas guerras em nome da defesa do soberano, mas sim em defesa de todos, em um movimento paradoxal: populações inteiras destroem-se mutuamente em nome da necessidade de viver, ou seja, os massacres tornam-se vitais. Essa justificativa - de gestão da vida e da sobrevivência dos corpos e das raças - passa a ser utilizada pelos regimes para travar guerras que causam mortes em massa. Nesse rumo, quanto mais a tecnologia das guerras se volta para a destruição exaustiva, tanto mais as decisões que 
deflagram e encerram as guerras são tomadas em função da questão nua e crua da sobrevivência.

Assim, considera-se que o racismo assegura, na economia do biopoder, a função de morte, a partir do princípio de que a morte dos outros representa o fortalecimento da própria pessoa na medida em que ela é membro de uma raça ou população, ou seja, configura-se enquanto elemento de uma pluralidade unitária e viva. E é justamente aqui que reside a particularidade do racismo moderno: ela habita no fato de que ele não se encontra ligado a mentalidades, ideologias ou mentiras do poder, mas à técnica ou tecnologia do poder, atrelado ao funcionamento de um Estado que é obrigado a se utilizar da raça - da sua eliminação e da sua purificação - para que possa exercitar seu poder soberano.

\section{CONCLUSÕES}

Diante da análise empreendida no presente artigo, pode-se afirmar que a guerra, instrumentalizada pela biopolítica, acaba por se transformar em um "regime de biopoder, ou seja, em uma forma de governo destinada não apenas a controlar a população, mas a produzir e a reproduzir todos os aspectos da vida social", de modo que "a vida cotidiana e o funcionamento normal do poder passaram a ser permeados pela ameaça da violência da guerra" (HARDT; NEGRI, 2005, p. 34, grifo do autor). Nesse rumo, o limite traçado pela sociedade a fim de definir quem são os homens sacros tende, a partir da lógica da guerra, a alargar-se, de modo que, como assevera Agamben (2010, p. 135), "no novo horizonte biopolítico dos estados de soberania nacional" cada vida humana e cada cidadão carrega, em seu interior, essa possibilidade: “a vida nua não está mais confinada a um lugar particular ou em uma categoria definida, mas habita o corpo biológico de cada ser vivente."

$\mathrm{Na}$ contemporaneidade o estado de guerra global mencionado por Hardt e Negri (2005) demonstra que as proposições de Agamben (2010) acerca da virtual sacralidade de todo ser humano em um contexto de culminância dos processos cujos antecedentes nazistas foram apenas laboratórios apresentam-se como consequência inarredável. Agamben (2008, p. 155) afirma que "nem a vida nem a morte, mas a produção de uma sobrevivência modulável e virtualmente infinita constitui a tarefa decisiva do biopoder em nosso tempo."

A guerra enquanto regime de biopoder, no entanto, não se exerce apenas de modo negativo, no sentido de produção da morte, mas também no sentido positivo, ou seja, de produção da vida. Com efeito, o poder soberano não pode utilizar-se da pura produção da 
morte para manter-se. A virtualidade - ou possibilidade - da morte é que é responsável por esse efeito de controle absoluto dos corpos.

Além disso, não só a possibilidade da destruição em massa de toda a população é responsável pela manutenção do biopoder, mas também a individualização da violência: "quando chega a se individualizar em sua forma extrema, o biopoder transforma-se em tortura." (HARDT; NEGRI, 2005, p. 41). Essa afirmação se justifica na medida em que, na contemporaneidade, assiste-se a um processo de banalização da tortura, à sua generalização enquanto técnica de controle. A tortura representa "um dos principais pontos de contato entre a ação policial e a guerra" e representa "a outra face do estado de exceção e da tendência do poder político para se furtar ao império da lei”, uma vez que "de acordo com a lógica do estado de exceção, a tortura constitui uma técnica de poder essencial, inevitável e justificável." (HARDT; NEGRI, 2005, p. 42).

Em Guantánamo, por exemplo, métodos para obter confissões e informações por meio de tormentos físicos e psicológicos foram largamente utilizados. A privação do sono, dentre outras técnicas para desorientar os prisioneiros, ao lado de outras formas de humilhação, foram implementadas sem escrúpulos em nome da eficiência na guerra ao terror.

Hoje, a prevenção do terrorismo de massa tende a apropriar-se de suas modalidades e a reproduzi-las, o que está evidenciado por Esposito (2006, p. 17) no seguinte exemplo: “que en la reciente guerra en Afeganistán los mismos aviones hayan lanzado bombas y víveres sobre las mismas poblaciones es quizás la señal tangible de que superposición más acabada entre defensa de la vida y producción de muerte."

Trata-se tais técnicas, na visão de Agamben (2008, p. 155), de uma manifestação do projeto do biopoder contemporâneo de produção de uma sobrevivência modulável e virtualmente infinita, tendo em vista que "a ambição suprema do biopoder consiste em produzir em um corpo humano a separação absoluta entre o ser vivo e o ser que fala, entre a zoé e o bíos, o não-homem e o homem: a sobrevivência.” Isso significa que o poder soberano contemporâneo sustenta-se na exclusão que se materializa na permanência (sobrevivência) do excluído.

Nesse estado de coisas, a guerra deixa de ser a ultima ratio, ou seja, o elemento final das sequências de poder, para transformar-se na prima ratio, ou seja, no principal fundamento da própria política. A guerra assume a condição de única forma de coexistência global, cuja consequência, que não surpreende, é justamente uma multiplicação em excesso dos mesmos riscos que com a guerra se pretende evitar. Como resultado, tem-se uma superposição 
absoluta de valores opostos como paz e guerra, ataque e defesa. Em síntese: vida e morte se sobrepõem cada vez mais.

De outra maneira, compreende-se que "a aplicação constante e coordenada da violência torna-se condição necessária para o funcionamento da disciplina e do controle" e, para a consecução desse objetivo,

\begin{abstract}
a guerra deve desempenhar uma função constituinte ou reguladora: terá de tornar-se ao mesmo tempo uma atividade processual e uma atividade reguladora, de ordenação, criando e mantendo hierarquias sociais, uma forma de biopoder voltada para a promoção e a regulação da vida social. (HARDT; NEGRI, 2005, p. 45)
\end{abstract}

Nesse rumo, se a guerra era anteriormente regulada mediante estruturas jurídicas, ela é hoje a reguladora dessas estruturas, o que se obtém por meio da construção e da imposição de sua própria estrutura legal.

Esse caráter construtivo da guerra global nada tem a ver com o poder constituinte ou fundador em sentido próprio, típico das guerras revolucionárias modernas. A ideia, hoje, é de manutenção, ou seja, de reprodução e de regulação da ordem vigente, criando a lei e a jurisdição desde o interior. Por isso a guerra é menos voltada para a defesa frente a uma mega-ameaça coerente e mais centrada em miniameaças proliferantes, é menos preocupada com a destruição geral do inimigo e mais inclinada para a transformação e até mesmo a produção do inimigo. Antes de ter um sentido fundador, o caráter regulador da guerra na contemporaneidade visa justamente a deslocar e a sufocar qualquer possibilidade constituinte (emancipatória), posto que a guerra, atualmente, “tem a função de moldar o ambiente político global, tornando-se assim uma forma de biopoder no sentido positivo e produtivo." (HARDT; NEGRI, 2005, p. 48).

E aqui se retoma o tema inicial do terrorismo. É ele que acaba servindo como justificativa ideológica para o exercício desse poder regulador. Efetivamente, na medida em que a "guerra contra o terrorismo" se alastra na persecução a um inimigo que é abstrato e ilimitado, a aliança entre os amigos também assume proporções universais, afinal, "toda a humanidade pode unir-se contra um conceito ou prática abstrata como o terrorismo", já que "apresentar o inimigo como encarnação do mal serve para torná-lo absoluto, assim como à guerra contra ele, tirando-o da esfera política - o mal é o inimigo de toda a humanidade." (HARDT; NEGRI, 2005, p. 36).

É aqui que a presença constante de um inimigo e a ameaça intermitente da desordem que ele pode provocar assumem relevância: elas são necessárias para legitimar a violência, afinal, "quando a guerra constitui a base da política, o inimigo se torna a função constitutiva 
da legitimidade.” (HARDT; NEGRI, 2005, p. 55). E quanto mais abstrato e ubíquo, quanto mais fugidio e inapreensível, quanto mais desconhecido e invisível, mais medo o inimigo provoca e, reflexamente, reafirma a necessidade de mais e mais segurança.

\section{REFERÊNCIAS}

AGAMBEN, Giorgio. Estado de exceção. São Paulo: Boitempo Editorial, 2004.

. Homo sacer: o poder soberano e a vida nua I. Belo Horizonte: Editora UFMG, 2010.

Boitempo, 2008

O que resta de Auschwitz: o arquivo e a testemunha (Homo Sacer III). São Paulo: . Profanações. São Paulo: Boitempo, 2007.

BUTLER, Judith. Vida precaria: el poder del duelo y la violencia. Buenos Aires: Paidós, 2009.

CARL SCHMITT. Théologie politique. Paris: Gallimard, 1988.

CASTRO, Edgardo. Introdução a Giorgio Agamben: uma arqueologia da potência. Belo Horizonte: Autêntica Editora, 2012.

ESPOSITO, Roberto. Biopolítica y filosofia. Buenos Aires: Grama Ediciones, 2006.

FOUCAULT, Michel. Em defesa da sociedade: curso no Collège de France (1975-1976). 2. ed. São Paulo: WMF Martins Fontes, 2010.

. História da Sexualidade I: A Vontade de Saber. Rio de Janeiro: Edições Graal, 2012.

. Nascimento da biopolítica: curso dado no Collège de France (1978-1979). São Paulo: Martins Fontes, 2008b.

. Segurança, Território, População: curso dado no Collège de France (1977-1978). São Paulo: Martins Fontes, 2008a.

GIACOIA JUNIOR, Oswaldo. Sobre direitos humanos na era da bio-política. Kriterion: Revista de Filosofia. Belo Horizonte, n. 118, 2008. p. 267-308.

HARDT, Michael; NEGRI, Antonio. Multidão: guerra e democracia na era do Império. São Paulo: Record, 2005.

MARTINS, Jasson da Silva. Biopolítica e governamentalidade. In: MARTINS, Jasson da Silva (Org.). Ética, política e direito: inflexões filosóficas. São Leopoldo: Nova Harmonia, 2008. p. 161-173.

NASCIMENTO, Daniel Arruda. Do fim da experiência ao fim do jurídico: percurso de Giorgio Agamben. São Paulo: LiberArs, 2012. 
RUIZ, Castor M. M. Bartolomé. A sacralidade da vida na exceção soberana, a testemunha e sua linguagem: (re)leituras biopolíticas da obra de Giorgio Agamben. Cadernos IHU. São Leopoldo: Instituto Humanitas Unisinos. Ano 10, nº 39, 2012.

ZAFFARONI, Eugenio Raúl. O inimigo no direito penal. Rio de Janeiro: Revan, 2007.

ŽIŽEK, Slavoj. Bem-vindo ao deserto do real! São Paulo: Boitempo Editorial, 2003.

\section{THE PRODUCTION OF NAKED LIFE IN THE STATE OF GLOBAL WAR}

ABSTRACT: The paper analyses the biopolitical boundaries of the fight against terrorism in the global war environment. The Biopolitics is presented as the movement through which natural human life is implicated in the ways and calculations of the power. In this perspective, it is the study of the Biopolitics that makes it possible to understand the motives by which the contemporary man finds himself exposed to an unprecedented violence that allows to talk about a level of no distinction between right and violence, once the state of exception changes into a dominant paradigm of politics. The homo sacer is presented as allegorical, in order to understand such an atypical space, $i$. e., an environment in which the element excluded from the general norm is not, because of that, absolutely out of relation with it, but is kept in relation to the mentioned norm as a form of suspension: the norm applies to the exception by disapplying itself.

KEYWORDS: Biopolitics. Global war. State of exception. Terrorism.

Recebido: 3 de junho de 2014

Aprovado: 27 de janeiro de 2015 